Changes in the prevalence of asthma

\section{The ebb and flow of asthma}

\section{B G Toelle, G B Marks}

\section{More studies reporting international time trends will put us in a better position to explain the changing prevalence of asthma}

W

ithout ever fully understanding the reasons for the global increase in the prevalence of asthma during the later part of the 20th century, we are now faced with the challenge of explaining an apparent decrease in prevalence. A challenge indeed! During the 1980s and early 1990s several repeat cross sectional studies, conducted in widely varying regions of the world, reported an increase in the prevalence of symptoms of asthma, diagnosed asthma, and medication use for asthma. ${ }^{12}$ Although most studies relied on self-reported symptoms and diagnoses-and hence could be subject to reporting bias-at least one ${ }^{3}$ observed substantial changes in airway hyperresponsiveness, lending credence to the view that this was not simply related to changes in disease classification and labelling. Parallel increases in hospitalisation rates ${ }^{4}$ and mortality rates $^{5}$ also were consistent with a true rising tide of asthma. This trend led to major national and international initiatives to control the disease. $^{6-9}$

There are now several reports to suggest that the tide has turned. During 2004 there have been a number of repeat cross sectional studies from Hong Kong, ${ }^{10}$ Korea, ${ }^{11}$ Switzerland, ${ }^{12}$ the UK$^{13}$ Scotland, ${ }^{14}$ Belmont, Australia ${ }^{15}$ and Melbourne, Australia ${ }^{16}$ that have reported a levelling off in asthma prevalence. In some studies there has been a statistically significant decrease in the prevalence of asthma symptoms. Although numerous environmental factors-including indoor and outdoor air quality, infections, diet, sibship, breastfeeding, and pet ownership-have been linked to the aetiology of asthma in cross sectional studies, none of these provides a robust explanation for the previous increasing trend or the apparent reversal of that trend. This is particularly the case as the trends have been observed in a wide range of countries, including those with both a high and low baseline prevalence of asthma.

In this issue of Thorax Mommers et al report the results of a series of four repeat cross sectional studies in Dutch school children. ${ }^{17}$ The studies conducted in 1989, 1993, 1997, and 2001 measured respiratory symptoms and treatment in 8-9 year olds. The strengths of this series of consecutive studies are that all the studies included well over 1000 children and had participation rates of over 95\%. Identical sampling methods and questionnaires were used, giving us confidence that the results are representative of Dutch school children in this region and that the differences are not due to changes in measurement instruments.

Between 1989 and 2001 there was a downward trend in the prevalence of recent wheeze which was statistically significant for boys but not for girls. The largest reduction was over the most recent period (1997-2001). Over this 12 year period there was no statistically significant trend in the prevalence of shortness of breath, coughing with phlegm, or chronic cough, with the prevalence remaining fairly stable in both boys and girls. However, there was a significant trend towards an increased use of asthma medication by boys who reported recent wheeze over this period. Girls who reported recent wheeze also used more medication but this trend was not significant. So, in Dutch school children between 1989 and 2001 it appears as though the prevalence of asthma symptoms has remained stable or, in the case of recent wheeze, the prevalence has decreased while the use of asthma medication in those children who have symptoms has increased. This apparent paradox may contain a clue to the explanation for the recent trends.

The authors suggest that increasing use of treatment may be responsible for this trend by suppressing asthma symptoms in a larger proportion of the population. An alternative explanation is that the diagnosis of asthma is being used more sparingly in 2001 than it was in previous years. In other words, children with episodic or intermittent wheeze, who do not require asthma medication, may have been less likely to be labelled as having asthma symptoms in 2001. This would explain the observed increase in the proportion of symptomatic boys who used asthma medication during this period. The finding of no change in the prevalence of airway hyperresponsiveness between 1992 and 2002 in an Australian series ${ }^{15}$ tends to support the view that there has been no real change in disease prevalence over that period and, rather, the observed decreases in reports of asthma reflect more specific application of the diagnostic label in recent times.

Repeat cross sectional studies provide a useful insight into changes over time. Comparison of studies from different countries and regions are informative, but these comparisons have been limited by the lack of standardised methods between studies. The most accurate insights into international time trends will be gleaned from repeat cross sectional studies conducted as part of the major multicentre studies of the International Study of Asthma and Allergies in Childhood (ISAAC) and the European Community Respiratory Health Survey (ECRHS). Three of the studies from 2004 were repeat cross sectional studies from ISAAC. ${ }^{10} 16$ When we have more studies reporting international time trends, we will be in a better position to explain the ebb and flow of asthma.

Thorax 2005;60:87-88.

doi: $10.1136 /$ thx. 2004.038331

\section{Authors' affiliations}

B G Toelle, G B Marks, Woolcock Institute of Medical Research, Sydney, NSW 2050, Australia

G B Marks, University of Sydney, Sydney, NSW 2006, Australia

Correspondence to: $\operatorname{Dr} B$ Toelle, Woolcock Institute of Medical Research, P'O Box M77, Missenden Road Post Office, NSW 2050, Australia; bgł@woolcock.org.au

\section{REFERENCES}

1 Woolcock AJ, Peat JK. Evidence for the increase in asthma worldwide. Ciba Found Symp 997;206: 122-34.

2 Burney $\mathbf{P}$. The changing prevalence of asthma? Thorax 2002;57(Suppl II):ii36-9.

3 Peat JK, van den Berg RH, Green WF, et al. Changing prevalence of asthma in Australian children. BMJ 1994;308:1591-6.

4 Burney P. Asthma: evidence for a rising prevalence. Proc R Coll Physicians Edinb 993;23:595-600.

5 Burney P. Asthma deaths in England and Wales 1931-85: evidence for a true increase in asthma mortality. J Epidemiol Comm Health 1988:42:316-20.

$6 \mathrm{NHLBI/WHO}$. Global initiatives for asthma. Bethesda, MD: National Health Lung and Blood Institute, 1995:69-117.

7 National Asthma Education and Prevention Program. Expert Panel Report 2: Guidelines for the diagnosis and management of asthma. Bethesda, MD: National Institutes of Health National Heart, Lung, and Blood Institute, 1997.

8 British Thoracic Society, Research Unit of the Royal College of Physicians of London, King's Fund Centre, National Asthma Campaign 
Guidelines for management of asthma. I. Chronic persistent asthma. BMJ 1990;301:651-3.

9 Woolcock A, Rubinfeld AR, Seale JP, et al. Thoracic Society of Australia and New Zealand. Asthma management plan, 1989. Med J Aust 1989;151:650-3

10 Wong GWK, Leung TF, Ko FWS, et al. Declining asthma prevalence in Hong Kong Chinese schoolchildren. Clin Exp Allergy 2004;34:1550-5.

11 Hong S-J, Lee M-S, Sohn MH, et al. Self-reported prevalence and risk factors of asthma among Korean adolescents: 5-year follow-up study, 1995-2000. Clin Exp Allergy 2004;34:1556-62.
12 Braun-Fahrländer C, Gassner M, Grize L, et al. No further increase in asthma, hay fever and atopic sensitisation in adolescents living in Switzerland. Eur Respir J 2004:23:407-13.

13 Anderson HR, Ruggles R, Strachan DP, et al Trends in prevalence of symptoms of asthma, hay fever, and eczema in 12-14 year olds in the British Isles, 1995-2002: questionnaire survey. BMJ 2004;328:1052-3.

14 Devenny A, Wassall H, Ninan T, et al. Respiratory symptoms and atopy in children in Aberdeen: questionnaire studies of a defined school population repeated over 35 years. BMJ 2004;329:489-90.
15 Toelle BG, $\mathrm{Ng} \mathrm{K}$, Belousova E, et al. Prevalence of asthma and allergy in schoolchildren in Belmont, Australia: three cross sectional surveys over 20 years. BMJ 2004;328: 386-7.

16 Robertson CF, Roberts MF, Kappers JH Asthma prevalence in Melbourne schoolchildren have we reached the peak? Med J Aust 2004; 180:273-6.

17 Mommers M, Gielkens-Sijstermans C, Swaen GMH, et al. Trends in the prevalence of respiratory symptoms and treatment in Dutch children over a 12 year period: results of the fourth consecutive survey. Thorax 2005;60:000-0.

\section{Angiogenesis and vascular endothelial growth factor in COPD}

\section{A J Knox, J Stocks, A Sutcliffe}

\section{A possible role for VEGF in the pathology of asthma and COPD}

t has been recognised for several hundred years that the bronchial vasculature is an extensive one with early descriptions by Ruysch and possibly Da Vinci. ${ }^{1}$ However, its function and regulation in health and in disease remain poorly understood. Studies a number of years ago suggested an increased number of bronchial vessels in asthma where increased collagen IV staining, a marker of new vessels, was seen in bronchial biopsies of asthmatic airways compared with controls. ${ }^{2}$ Subsequent studies by the same group and by Salvato and colleagues have confirmed the presence of angiogenesis in the bronchial circulation in asthma. ${ }^{34}$ There are a number of candidate angiogenic factors for these changes, perhaps the most important of which are vascular endothelial growth factor (VEGF) and the angiopoietins which are distinct molecules that act together at different stages of angiogenic processes in several biological systems. ${ }^{5-11}$ Other molecules with angiogenic potential are fibroblast growth factor, ${ }^{9}$ angiogenin, ${ }^{9}$ and chemokines such as interleukin (IL)- $8^{12}$ and eotaxin. ${ }^{13}$ Interestingly, angiogenesis seems to be a feature of inflammatory diseases at a number of sites in the body including the joints ${ }^{14}$ and the gut. ${ }^{15}$

The study published in this issue of Thorax by Kranenburg and colleagues ${ }^{16}$ suggests that bronchial vascular changes may also occur in chronic obstructive pulmonary disease (COPD). The authors measured the cellular expression pattern of VEGF and its receptors Flt- 1 and KDR/Flk- 1 by immunohistochemistry in central and peripheral airways obtained from ex-smokers with or without COPD. They found that VEGF Flt-1 and KDR/Flt- 1 immunostaining was localised in vascular and airway smooth muscle cells, epithelial cells, and macrophages. In contrast, the endothelial cells did not express VEGF but did express its receptors, consistent with them being effector cells for VEGF to act on rather than an important autocrine source.

VEGF expression on bronchial tissues was higher in patients with COPD than in those without COPD. VEGF exists as at least five gene products A-E with VEGF-A being the most potent. ${ }^{17}$ VEGFA has several spliced variants which are expressed by airway cells. ${ }^{17}$ A number of conditions relevant to COPD have been shown to increase VEGF expression and release including cigarette smoke, ${ }^{18}$ hypoxia, ${ }^{19}$ and cytokines such as IL- $1 \beta$ and transforming growth factor (TGF)$\beta .^{20}$

What is the significance of VEGF expression patterns in the bronchial vessels in asthma and COPD and how might VEGF contribute to the pathology of these diseases? Increased airway wall thickening would cause enhanced airway narrowing on stimulation with constrictor agents, thereby contributing to bronchial hyperresponsiveness. An increased bronchial vasculature would increase inflammatory cell trafficking and exudation and transudation of mediators, particularly if vascular permeability was altered. The increased vasculature could also contribute to airway hyperresponsiveness by supporting the increased airway smooth muscle mass which is a feature of both asthma and COPD. ${ }^{21}$ Interestingly, the study by Kranenburg et al ${ }^{16}$ showed increased staining in bronchial smooth muscle consistent with this hypothesis. An alternative hypothesis, however, is that the increase in the bronchial vasculature is a protective mechanism which results in increased clearance of proinflammatory mediators and cytokines from inflamed airways. Studies in mouse models have helped to shed light on this issue. Lee $e^{2} a^{22}$ showed that VEGF was increased in the lungs in a mouse model of asthma and that VEGF receptor inhibitors inhibited cellular influx as well as inhibiting airway hyperresponsiveness and reducing microvascular leakage.

Interestingly, a number of treatments for airway diseases can modify VEGF production. Glucocorticoids reduce VEGF secretion by structural ${ }^{17}$ and inflammatory airway cells ${ }^{23}$ in vitro and both glucocorticoids and long acting $\beta$ agonists have been shown to reduce the vascularity of asthmatic airways in vivo. ${ }^{23}$ The effect of these agents on VEGF expression and angiogenesis in COPD has not yet been studied but would be interesting to determine. This suggests that strategies targeting VEGF may have a beneficial effect on bronchial wall inflammation and remodelling, at least in asthma. The situation may be more complex in COPD, however, due to coexisting emphysema and pulmonary hypertension.

In addition to studying VEGF expression in bronchial and bronchiolar walls, Kranenburg et al $^{16}$ also looked at VEGF staining in the alveolar spaces and pulmonary vessels. They found that the epithelial and endothelial cells in the alveolar spaces and the distal airways 
were intensively positive for VEGF in patients with COPD. They hypothesise that VEGF secreted by these cells may be involved in the establishment and maintenance of the function of the blood-gas interface. Studies in animal models suggest that VEGF and its receptors play a protective role in the development of emphysema. Kasahara et $a^{24}$ have shown that inhibition of VEGF receptors with the specific receptor inhibitor SU5416 can cause alveolar cell apoptosis and the development of emphysema in rats. These findings are of interest as they suggest that the increased VEGF expression in the distal airspaces seen by Kranenburg et al ${ }^{16}$ may be a protective compensating mechanism. Collectively, these studies suggest a paradoxical role for VEGF in the bronchi and air spaces in COPD-with a protective role in the alveolus but a detrimental function in the bronchi and bronchioles.

The situation becomes more complex still when changes in the pulmonary circulation are taken into account. Kranenburg et al ${ }^{16}$ showed that VEGF expression was increased in the pulmonary vessels in COPD, suggesting a potential role in the development of pulmonary hypertension. There is an extensive literature going back over 10 years looking at the role of VEGF and its receptors in pulmonary hypertension. Pulmonary hypertension is characterised by plexiform lesions in pulmonary vessels and VEGF is expressed inside the plexiform lesions as well as in smooth muscle adjacent to the lesions. ${ }^{25}$ Data from animal models suggest that VEGF may have a protective role as inhibition of the VEGF receptor II combined with chronic hypoxia causes cell death dependent pulmonary endothelial cell proliferation and severe pulmonary hypertension. ${ }^{26}$ Moreover, overexpression of VEGF using cell based gene transfer reduced monocrotaline induced pulmonary hypertension in rats, ${ }^{27}$ and similar findings were reported with adenoviral mediated overexpression in a chronic hypoxia rat model. ${ }^{28}$

The paper by Kranenburg et al is therefore an important one which raises many questions about VEGF in COPD. VEGF and its receptors are involved in many processes in COPD including bronchial wall remodelling, emphysema, and pulmonary hypertension. The complexity of these roles suggests that strategies specifically targeting VEGF in COPD would have unpredictable and possibly opposing effects on some of the different processes.

Over the next few years we are likely to find out a great deal more about the importance of the role of angiogenic processes in a number of different lung diseases and the role that VEGF, its receptors, and other angiogenic factors play in several situations.

\section{ACKNOWLEDGEMENTS}

The authors thank Rachel Small and Heather Hickman for secretarial support.

Thorax 2005;60:88-89.

doi: $10.1136 /$ thx.2004.030544

Authors' affiliations

A J Knox, J Stocks, A Sutcliffe, Division of Respiratory Medicine, Nottingham City Hospital, Nottingham NG5 IPB, UK

Correspondence to: Professor A J Knox, Division of Respiratory Medicine, Clinical Sciences Building, Nottingham City Hospital, Hucknall Road, Nottingham NG5 1PB, UK; alan.knox@nottingham.ac.uk

\section{REFERENCES}

1 Mitzner W, Wagner E. On the purported discovery of the bronchial circulation by Leonardo da Vinci. J Appl Physiol 1992;73:1196-201.

2 Orsida BE, Ward C, Li X, et al. Effect of a long acting $\beta_{2}$-agonist over three months on airway wall vascular remodeling in asthma. Am J Respir Crit Care Med 2001; 164:117-21.

3 Orsida BE, Li X, Hickey B, et al. Vascularity in asthmatic airways: relation to inhaled steroid dose. Thorax 1999;54:289-95.

4 Salvato G. Quantitative and morphological analysis of the vascular bed in bronchial biopsy specimens from asthmatic and non-asthmatic subjects. Thorax 2001:56:902-6.

5 Asai K, Kanazawa H, Kamoi H, et al. Increased levels of vascular endothelial growth factor in induced sputum in asthmatic patients. Clin Exp Allergy 2003;33:595-9.

6 Kanazawa H Hirata K Yoshikawa J Involvement of vascular endothelial growth factor in exercise induced bronchoconstriction in asthmatic patients. Thorax 2002;57:885-8.

7 McDonald DM. Angiogenesis and remodeling of airway vasculature in chronic inflammation. Am J Respir Crit Care Med 2001;164:S39-45

8 Hoshino M, Nakamura Y, Hamid QA. Gene expression of vascular endothelial growth factor and its receptors and angiogenesis in bronchial asthma. J Allergy Clin Immunol 2001; 107:1034-8

9 Hoshino M, Takahashi M, Aoike N. Expression of vascular endothelial growth factor, basic fibroblast growth factor, and angiogenin immunoreactivity in asthmatic airways and its relationship to angiogenesis. J Allergy Clin Immunol 2001;107:295-301.

10 Yancopoulos GD, Davis S, Gale NW, et al. Vascular-specific growth factors and blood vesse formation. Nature 2000;407:242-8.

11 Ribatti D, Vacca A, Presta M. The discovery of angiogenic factors: a historical review. Gen Pharmacol 2000;35:227-31.
12 Tanner JE. Nucleosomes activate NF-kappaB in endothelial cells for induction of the proangiogenic cytokine IL-8. Int J Cancer 2004:112:155-60.

13 Salcedo R, Young HA, Ponce ML, et al. Eotaxin (CCL11) induces in vivo angiogenic responses by human CCR3+ endothelial cells. J Immunol 2001;166:7571-8.

14 Walsh DA. Angiogenesis in osteoarthritis and spondylosis: successful repair with undesirable outcomes. Curr Opin Rheumatol 2004; 16:609-15.

15 Kanazawa S, Tsunoda T, Onuma E, et al. VEGF, basic-FGF, and TGF-beta in Crohn's disease and ulcerative colitis: a novel mechanism of chronic intestinal inflammation. Am J Gastroenterol 2001;96:822-8.

16 Kranenburg AR, de Boer WI, Alagappan VKT, et al. Enhanced bronchial expression of vascular endothelial growth factor and receptors (Flk-1 and Flt-1) in patients with chronic obstructive pulmonary disease. Thorax 2005:60:106-13.

17 Knox AJ, Corbett L, Stocks J, et al. Human airway smooth muscle cells secrete vascular endothelial growth factor: up-regulation by bradykinin via a protein kinase $C$ and prostanoid-dependent mechanism. FASEB J 2001;15:2480-8.

18 Wright JL, Tai H, Churg A. Cigarette smoke induces persisting increases of vasoactive mediators in pulmonary arteries. Am J Respir Cell Mol Biol, 2004 (epub ahead of print)

19 Nilsson I, Shibuya M, Wennstrom S. Differential activation of vascular genes by hypoxia in primary endothelial cells. Exp Cell Res 2004;299:476-85.

20 Wen FQ, Liu X, Manda W, et al. TH2 Cytokineenhanced and TGF-beta-enhanced vascular endothelial growth factor production by cultured human airway smooth muscle cells is attenuated by IFN-gamma and corticosteroids. J Allergy Clin Immunol 2003;111:1307-18.

21 Jeffery PK. Remodeling in asthma and chronic obstructive lung disease. Am J Respir Crit Care Med 2001;164:S28-38.

22 Lee YC, Kwak YG, Song CH. Contribution of vascular endothelial growth factor to airway hyperresponsiveness and inflammation in a murine model of toluene diisocyanate-induced asthma. J Immunol 2002;168:3595-600.

23 Horiuchi T, Weller PF. Expression of vascular endothelial growth factor by human eosinophils: upregulation by granulocyte macrophage colonystimulating factor and interleukin-5. Am J Respir Cell Mol Biol 1997; 17:70-7.

24 Kasahara Y, Tuder RM, Taraseviciene-Stewart L et al. Inhibition of VEGF receptors causes lung cell apoptosis and emphysema. J Clin Invest 2000;106:1311-9.

25 Tuder RM, Chacon M, Alger L, et al. Expression of angiogenesis-related molecules in plexiform lesions in severe pulmonary hypertension: evidence for a process of disordered angiogenesis. J Pathol 2001;195:367-74.

26 Taraseviciene-Stewart L, Kasahara Y, Alger L, et al. Inhibition of the VEGF receptor 2 combined with chronic hypoxia causes cell death-dependent pulmonary endothelial cell proliferation and severe pulmonary hypertension. FASEB $J$ 2001;15:427-38.

27 Campbell Al, Zhao Y, Sandhu R, et al. Cell-based gene transfer of vascular endothelial growth factor attenuates monocrotaline-induced pulmonary hypertension. Circulation 2001; 104:2242-8

28 Partovian C, Adnot S, Raffestin B, et al. Adenovirus-mediated lung vascular endothelial growth factor overexpression protects against hypoxic pulmonary hypertension in rats. Am J Respir Cell Mol Biol 2000:23:762-71. 
Tuberculin testing

\section{Tuberculin testing, BCG and tuberculosis today}

\section{J Moore-Gillon}

\section{Little progress has been made in the last 50 years}

$\checkmark$ uberculosis is not simply a problem hanging over from the past-it is a growing challenge-but what are the risks of acquiring tuberculosis infection in childhood, and how should those risks be assessed?

In this issue of Thorax Leung and colleagues $^{1}$ analyse the results of tuberculin skin testing in over 21000 children in Hong Kong aged 6-9 years between October 1999 and February 2000. $99 \%$ of the children had received BCG vaccination in the neonatal period. The authors used three different approaches to the data to estimate the subsequent annual risk of tuberculous infection. In broad terms, one approach used the size of the tuberculin response to assess whether infection had occurred, using a cut off point of $\geqslant 10 \mathrm{~mm}$ induration after skin testing with one unit of tuberculin. They then used age (which equals the number of years each child had been at risk of infection) to estimate the annual risk. This is the "classic" method. The second approach estimated the annual risk of infection by comparing the rates of tuberculin positivity in the 8-9 year old age group with those in the 6-7 year old group. The third estimated the prevalence of infection by locating a secondary peak in the tuberculin reaction distribution curve and assuming that, among those with tuberculosis infection, there would be a symmetrical distribution of reaction sizes around this peak. Age can then be used to calculate the annual risk of infection.

The first and second of these methods are conventionally used to estimate the annual risk of tuberculous infection, and such estimates are necessary as part of the calculations made about the cost effectiveness of BCG programmes. Leung et al show, however, that in their population the first and second methods gave estimates for the annual risk of infection which were some three times higher than the estimate produced by the third method. It would be easy to conclude that the third ("secondary peak") method is not a valid approach which underestimates the risk. It is, however, this third non-conventional method which gives an estimate for the annual risk of infection which agrees best with that which would be expected from the prevalence of active tuberculous disease (in contrast to tuberculous infection) in children.

If these findings are applicable to other populations, what is their importance? This paper refers to a population with prior (neonatal) BCG vaccination, and it is possible that the tuberculin skin test is a poor indicator of infection in the presence of BCG. Certainly, it makes it more difficult to interpret the test in the clinical context. The principles by which the results have been analysed appear, however, to be equally applicable to a population which has not been near universally vaccinated, and the results suggest that the actual risk of tuberculous infection may be lower than that implied by "conventional" methods of its calculation. This may influence decisions about the cost effectiveness of mass BCG vaccination programmes, such as that currently offered to 1314 year olds in the UK.

But there are wider issues here. The authors have used the very best available methods of testing for tuberculous infection. These tests are part of the screening programme which is carried out before offering BCG vaccinationthe vaccine which is again the very best available. It is, however, a poor reflection on the priority which has been accorded tuberculosis that exactly the same study could have been carried out decades ago, because neither the best method of diagnosing tuberculous infection nor the best vaccine against tuberculosis have changed at all in that time. Quite clearly, this is not a criticism of these authors: they have carried out a first class study with the latest fully validated tools available. The trouble is that, in this area, "latest" means 50 or more years old. Investigation of new diagnostic techniques for tuberculous infection (rather than disease) and the development of new vaccines have indeed been going on, largely by a limited number of research groups who have struggled to find funding for their programmes. It is a reflection on funding bodies and political prioritiesnot the quality of the researchers-that, unlike probably any other disease, the "gold standard" for this study as carried out in 2000 was the same as it would have been had it been carried out in 1950.

How good is that gold standard? Not that good. The value of tuberculin testing as an indicator of tuberculous infection is hindered by prior BCG vaccination and by exposure to environmental mycobacteria, hence the complex assumptions about the relationship between tuberculin dose and reaction size which have to be made by these and all other authors. The efficacy of BCG vaccination varies widely in different populations throughout the world, and even at its very best it does not approach the levels of protection achieved with vaccines against other diseases.

Progress is being made in finding better ways of identifying latent tuberculous infection. The identification of antigen specific $\mathrm{T}$ cells in individuals infected with $M$ tuberculosis may be achieved by demonstrating the release of interferon- $\gamma$ when they are appropriately stimulated. ${ }^{23}$ If the antigens ESAT- 6 or CFP10 are used, discrimination is possible between individuals who have been infected with $M$ tuberculosis and those who have received prior BCG vaccination $^{4}$ - a clear advantage over tuberculin testing.

Turning to vaccine development, matters are less far forward. Many approaches have been tried in animal models but few are at the stage of even phase 1 clinical trials. Possible new vaccines are usually modified forms of BCG, are mutant strains of $M$ tuberculosis, or are prepared from subunits of $M$ tuberculosis. ${ }^{6} \mathrm{New}$ vaccines now have to overcome the hurdle of being safe to use in at least the great majority of HIV positive individuals if their benefits are to outweigh their risks in many populations at risk of TB. A greater understanding of the mycobacterial genome undoubtedly helps in identifying possible ways forward, ${ }^{7}$ but at the present rate of research progress a replacement for BCG is some way off.

There is, then, much to learn from the study carried out by Leung and colleagues. At the most superficial level, it reminds us that tuberculosis remains a threat to children; it ought not to be. It then suggests that the methodology usually used for estimating the annual risk of tuberculous infection in children may be inappropriate, with consequences for screening and BCG programmes. Finally, the nature of the tools that were available to the authors shows that there has been a comprehensive failure on the part of the 
political and medical establishment to invest adequately in research into one of the leading infectious threats to global health.

Thorax 2005;60:90-91.

doi: 10.1136/thx.2004.028746

Correspondence to: Dr J Moore-Gillon, Department of Respiratory Medicine, St Bartholomew's and Royal London Hospitals, London EClA 7BE, UK; john.moore-gillon@ bartsandthelondon.nhs.uk

\section{REFERENCES}

1 Leung $\mathrm{CC}$, Yew WW, Tam CM, et al. Tuberculin response in BCG vaccinated schoolchildren and the estimation of annual risk of infection in Hong Kong. Thorax 2005;60:124-9.

2 Mazurek GH, LoBue PA, Daley CL, et al. Comparison of a whole-blood interferon gamma assay with tuberculin skin testing for detecting latent Mycobacterium tuberculosis infection. JAMA 2001;286: 1740-7.

3 Lalvani A, Pathan AA, McShane H, et al. Rapid detection of Mycobacterium tuberculosis infection by enumeration of antigen-specific $T$ cells. Am J Respir Crit Care Med 2001;163:824-8.
4 Lalvani A. Spotting latent infection: the path to better tuberculosis control. Thorax 2003:58:916-8.

5 Brock I, Weldingh K, Lillebaek T, et al. Comparison of tuberculin skin test and new blood test in tuberculosis contacts. Am J Respir Crit Care Med 2004;170:65-9

6 Fruth U, Young D. Prospects for new TB vaccines: Stop TB working group on TB vaccine development. Int J Tuberc Lung Dis 2004:8:151-5

7 Kana Bavesh D, Mizrahi V. Molecular genetics of Mycobacterium tuberculosis in relation to the discovery of novel drugs and vaccines. Tuberculosis 2004;84:63-75.

PEF data plot

\section{The PEF data plot: planning to get the message}

\section{R Miller}

\section{Work is needed to determine the best scaling for PEF data to enable patients and clinicians to get the most benefit from them}

A large part of medical practice involves pattern recognition. A clinician may note that a few key aspects of a patient's history, their demographic data, their clinical examination, and chest radiograph fit a pattern they recognise as making a particular diagnosis highly probable. This pattern involves more than one domain of data acquisition, and both within and between these domains our ability to recognise patterns may be affected by how the information is presented to us. If data are presented to us verbally, the ordering of this information may be crucial. For example, verbal instructions on how to get from ward A to ward B are easier to understand and use if they are given in consecutive order starting from ward A and ending up at ward $B$ rather than the instructions coming in random order. The order in which a patient's history is presented to a colleague is an example of this. The graphical presentation of tables of numbers may improve the usefulness of the data, ${ }^{1}$ especially if there is a shape in the data that conveys the signal and the time required to search the data for any signal is thereby reduced. ${ }^{2}$ In this issue of Thorax Reddel and colleagues ${ }^{3}$ question whether we are doing enough to present our patients' peak expiratory flow (PEF) data in a manner that is likely to facilitate both clinicians and patients distinguishing the signal or message in the data from all the noise.

Research continues to add to our understanding of how the brain detects and learns patterns. Facial recognition and the interpretation of facial expression are key aspects of human interaction involving complex pattern recognition. The ability of a clinician to interpret subtle changes in facial expression of patients during a consultation is important to ensure optimum communication has been achieved. Functional imaging has shown that specific areas of the brain-the fusiform face area on the inferior surface of the temporal lobe and the occipital face area-are involved in face recognition. ${ }^{4}$ Recent functional magnetic resonance evidence indicates that these areas appear to be used for expert or higher level recognition irrespective of the type of image under consideration. $^{5}$ Research into whole person recognition, which involves the assessment of the face and body habitus, has found that the ability to recognise people was not impaired by showing the subjects in different postures whereas changes in the subjects' clothing did impair it. ${ }^{6}$ This indicates that related visual effects can be distracting and alter our ability to recognise patterns in complex visual data. So, when constructing charts or graphs to display data, we must be careful that all non-essential items ("chart junk") are left out. The trend to use three dimenstional graphics where two dimensional would suffice is an example of unnecessary distracting information; the exact projection of the top of a three dimensional bar or column onto the relevant axis is often distorted by the three dimensional effect. A recent survey of American medical journals found that, in 74 pharmaceutical graphical presentations, $66 \%$ contained "chart junk", 46\% had redundancy in the presentation, and over a third had numerical distortion. ${ }^{7}$

PEF variability is a helpful signal in the diagnosis and management of asthma. If PEF readings are presented as just a stream of numbers on a sheet of paper, which some patients will offer up in the clinic, it is a laborious process to check through these to find out what is going on. Graphical presentation of the data will help, but it has been shown that subjects serially process only fixed amounts of data at a time and so some types of graphical display are better than others in getting the information across quickly. ${ }^{8}$ The way data are presented on graphs or diagrams can therefore influence our ability to spot any signal. Reddel and colleagues ${ }^{3}$ point out that the abscissa scale for PEF plots has not been standardised. They found that each of 17 different PEF charts they obtained had slightly different scales. They have indicated that, if PEF data are plotted on a compressed time scale, then the ability to detect a true change in PEF is enhanced. Another example of this effect of scaling in respiratory practice is the presentation of flow-volume loops where incorrect scales will distort the data and may falsely suggest to the observer the presence of upper airway obstruction. The ATS document for standardising spirometry indicates the optimum scaling for presenting flow-volume loops ( $2 \mathrm{l} / \mathrm{s}$ of flow against 1 litre of volume) to avoid this sort of error. ${ }^{9}$

Computers can be used to help identify patterns in data by the training of neural networks and this approach has been successfully applied to the recognition of upper airway obstruction from flow-volume curves. $^{10}$ For PEF data, discriminant analysis was employed by Gannon et $a l^{11}$ to facilitate the recognition of work related changes in PEF and their computer program has led to improved sensitivity and specificity when diagnosing occupational asthma. Statistical process control (SPC) techniques $^{12}$ have been applied 


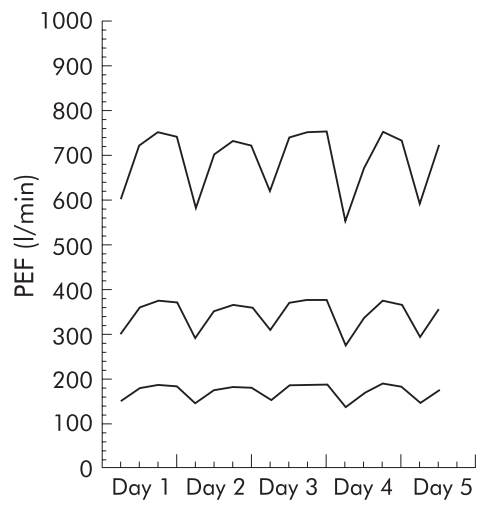

Figure 1 PEF data for three patients on a linear ordinate scale.

to PEF data as a means for improving the detection of true signals in the data. This technique assumes that the data should vary randomly following a Gaussian distribution and so newly acquired data points are compared with an estimate of the usual level of variation about the mean, which is the standard deviation (SD) of the data. A significant deviation from the baseline state is judged to have occurred if a single data point is more than 3 SD from the mean, or two of three sequential data are between 2 and 3 SD from the mean, or four of five sequential data are between 1 and 2 SD, or eight successive data are between 0 and 1 SD from the mean. ${ }^{12}$ The assumption of a Gaussian distribution may be true for once a day morning pre-bronchodilator PEF values and this technique has been successfully applied for the detection of changes from baseline in otherwise stable patients. ${ }^{13}$ If several data points a day are used for asthmatics who have a large morning dip in PEF, then this assumption may no longer be correct as there are, in fact, two populations of results being lumped together. The application of SPC may not therefore be so helpful for other applications of PEF data, such as the diagnosis or monitoring of recovery from an acute attack.

The above control charting method requires an estimate of the baseline mean value and its variance which are hard to obtain from hand recorded data. The use of data logging meters facilitates this approach and they are now available for under $£ 10$ ( 15 euros), with associated PC software about twice this cost. The micro chips in these devices usually have spare capacity, so interactive meters that are tailored to the subject and their requirements are entirely feasible. The use of SPC on daily PEF values could easily be implemented and, if threshold criteria as above are breeched, then patients could be prompted to change their treatment and timing of PEF measurements to

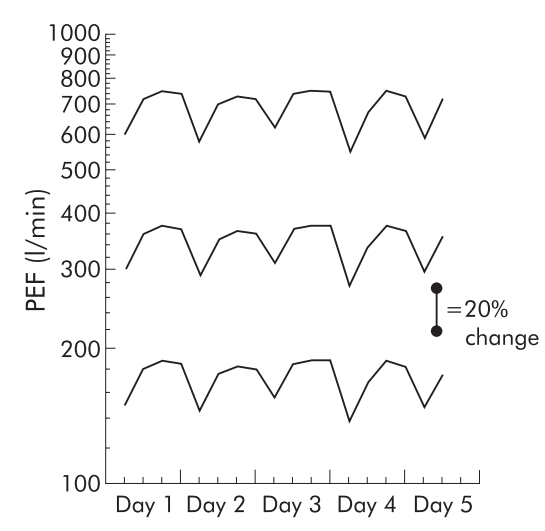

Figure 2 The same PEF data as in fig 1 on a log ordinate scale.

ensure control of their asthma is rapidly regained. The optimum abscissa scale for PEF charting will therefore need to vary according to purpose. For assessing stable asthmatics with a control chart, a once a day reading is needed and a compressed time scale is ideal. Reddel and colleagues have previously proposed an alternative method using the lowest morning pre-bronchodilator PEF in the week expressed as a percentage of recent best or predicted as the preferred indicator of control. ${ }^{14}$ However, in occupational asthma readings of up to every 2 hours may be needed to detect a work related change in lung function, ${ }^{15}$ and this frequency may initially be the minimum required to monitor recovery from a severe asthma attack.

The choice of abscissa scale may not be the only issue. An abstract some years ago at a British Thoracic Society meeting suggested that a log ordinate scale for PEF might be an improvement. The degree of variation in PEF is the main point of interest for helping with the diagnosis of asthma, and a $20 \%$ change from best value has been found to be associated with asthma. ${ }^{16}{ }^{17}$ Using a log scale for PEF might facilitate recognising this from the data. For example, in fig 1 there are three sets of identically patterned data each with different mean PEF. Plotting these data with PEF on a log scale as in fig 2 makes it more obvious that these all have identical percentage variation.

We must therefore be sure that we are always presenting PEF data (or any other data) to best advantage. As Reddel and colleagues argue, ${ }^{3}$ if we do not do this for our asthma patients then we let them down and undermine their efforts to help in the monitoring of their condition. In future, cheap electronic peak flow meters with data logging capability will increasingly be used and the graphical presentation of the data can be flexible and optimised for the purpose, be it once a day readings for stable monitoring, 4 times a day monitoring of recovery from an acute exacerbation, or 2 hourly or more frequent readings for occupational settings and severe attacks. The respiratory community should now work to determine the best scaling for these various purposes together with the best algorithms for detecting true changes in the PEF data. Only then will patients and clinicians get the most benefit from these data.

Thorax 2005;60:91-92. doi: $10.1136 /$ thx.2004.035782

Correspondence to: $\operatorname{Dr} M$ R Miller, Department of Medicine, University Hospitals Trust, Birmingham B29 6JD, UK; martin.miller@uhb. nhs.uk

\section{REFERENCES}

1 Jarvenpaa SL, Dickson GW. Graphics and managerial decision making: research based guidelines. Communications of the ACM 1988:31:764-74.

2 Larkin JH, Simon HA. Why a diagram is (sometimes) worth 10,000 words. Cognitive Science 1987;11:65-100.

3 Reddel HK, Vincent SD, Civitico J. The need for standardisation of peak flow charts. Thorax 2005;60: 164-7.

4 Sergent J, Ohta S, MacDonald B. Functional neuroanatomy of face and object processing: a positron emission tomography study. Brain 1992;115:15-36.

5 Gauthier I, Skudlarski P, Gore JC, et al. Expertise for cars and birds recruits brain areas involved in face recognition. Nat Neurosci 2000;3:191-7.

6 Seitz K. The effect of changes in posture and clothing on the development of unfamiliar person recognition. Appl Cognitive Psychol 2003; 17:819-32.

7 Cooper RJ, Schriger DL, Wallace RC, et al. The quantity and quality of scientific graphs in pharmaceutical advertisements. J Gen Intern Med 2003; 18:294-7.

8 Legge GE, Gu YC, Luebker A. Efficiency of graphical perception. Percept Psychophys 1989:46:365-74.

9 American Thoracic Society. Standardization of spirometry 1994 update. Official statement of the American Thoracic Society. Am J Respir Crit Care Med 1995; 152:1107-36.

10 Bright $P$, Miller MR, Franklyn JA, et al. The use of a neural network to detect upper airway obstruction caused by goiter. Am J Respir Crit Care Med 1998; 157:1885-91.

11 Gannon PF, Newton DT, Belcher J, et al. Development of OASYS-2: a system for the analysis of serial measurement of peak expiratory flow in workers with suspected occupational asthma. Thorax 1996;51:484-9.

12 Boggs PB. Peak expiratory flow rate control chart: a breakthrough in asthma care. Ann Allergy Asthma Immunol 1996;77:429-32.

13 Boggs PB, Wheeler D, Washburne WF. Peak expiratory flow rate control chart in asthma care: chart construction and use in asthma care. Ann Allergy Asthma Immunol 1998;81:552-62.

14 Reddel HK, Salome CM, Peat JK, et al. Which index of peak expiratory flow is most useful in the management of stable asthma? Am J Respir Crit Care Med 1995;151:1320-5.

15 D'Alonzo GE, Steinijans VW, Keller A. Measurements of morning and evening airflow grossly underestimate the circadian variability of $\mathrm{FEV}_{1}$ and peak expiratory flow rate in asthma. Am J Respir Crit Care Med 1995:152:1097-9.

16 Higgins BG, Britton JR, ChinnS, et al. The distribution of peak flow variability in a population sample. Am Rev Respir Dis 1989; 140:1368-72.

17 Thiadens HA, De Bock GH, Dekker FW, et al Value of measuring diurnal peak flow variability in the recognition of asthma: a study in general practice. Eur Respir J 1998;12:842-7. 
Starting dose of ICS in adult asthma

\section{Optimal starting dose of inhaled corticosteroids in adult asthma: why has it taken so long?}

\section{Masoli, M Weatherall, R Beasley}

\section{Start at a dose considered to be appropriate for the severity of the disease, usually $400 \mu \mathrm{g}$ BDP or equivalent}

l: is disturbing to realise that, although inhaled corticosteroids have been prescribed for over three decades in the treatment of asthma, there are still major therapeutic issues associated with their use that have yet to be clearly determined. One of these issues is the optimal starting dose. This uncertainty is illustrated by the different approaches that have been proposed for starting inhaled corticosteroids in patients with asthma ranging from "start with a high dose then step down once control has been achieved", 12 "start with a dose of $400 \mu \mathrm{g}^{3}$ or $200-500 \mu \mathrm{g}$ per day beclomethasone dipropionate (BDP) or equivalent and then step up if required", ${ }^{4}$ or "start at the dose considered to be appropriate for the severity of disease, usually $400 \mu \mathrm{g}$ of BDP or equivalent". ${ }^{5}$

To address this uncertainty and determine the optimal starting dose of inhaled corticosteroids in adults with asthma, Powell and Gibson have undertaken a systematic review and metaanalysis of randomised controlled trials that have investigated this issue. Their findings were reported in a recent issue of Thorax ${ }^{6}$ and indicate that, for patients with asthma who require inhaled corticosteroids, there is no evidence of a difference in efficacy between commencing with a moderate dose $(400 \mu \mathrm{g}$ per day BDP or equivalent) compared with a high dose ( $\geqslant 800 \mu \mathrm{g}$ per day) and stepping down. An initial moderate dose of inhaled corticosteroids was more effective than an initial low dose $(200 \mu \mathrm{g}$ per day).

These findings are reassuring in that they do not support the "start high, step down" approach which has the potential to lead to inappropriately high doses of inhaled corticosteroids being used long term. This may occur if the patient does not attend for regular review so the initial dose becomes the long term maintenance dose, or if on medical review there is a reluctance to reduce the high dose in case it leads to worsening asthma control. The preferred approach demonstrated in this metaanalysis of initiating treatment with moderate doses of inhaled corticosteroids has advantages in terms of a better risk/benefit ratio and reduced economic cost. As discussed by the authors, the main limitations of their meta-analysis were the small number of studies which could be included in the subgroup analyses and the inability to examine severe exacerbations as an outcome measure as it was not reported in most of the included studies. However, despite these limitations, the findings from this meta-analysis represent the best integration of current scientific evidence and can be incorporated in consensus guidelines. In this regard, the current British guidelines represent the ideal recommendation-to start at a dose considered to be appropriate for the severity of disease, usually $400 \mu \mathrm{g}$ BDP or equivalent. ${ }^{5}$

The findings are also consistent with recent meta-analyses of the doseresponse relationship of inhaled corticosteroids in adult asthma. ${ }^{7-11}$ The initial meta-analysis showed that, for different outcome measures including lung function, symptoms, $\beta$ agonist use and exacerbations, at least $90 \%$ of the maximum efficacy can be achieved with a dose of fluticasone propionate (FP) of around $200 \mu \mathrm{g}$ per day. ${ }^{7}$ In the moderate to severe adult asthmatic patients included in the studies of the metaanalysis, the maximum therapeutic effect was achieved with a dose of FP of around $500 \mu \mathrm{g}$ per day. This metaanalysis challenged the dogma that existed at the time-that higher doses were required to achieve the maximal obtainable effect and that there were marked differences in the dose-response relationship for different clinical outcome measures. In particular, the dose of FP required to reduce exacerbations symptoms and improve lung function.

Similarly, in another meta-analysis of placebo controlled dose-response studies of FP, no significant differences was similar to that required to reduce were noted in the magnitude of change in morning peak flow in patients receiving high ( 500 or $1000 \mu \mathrm{g}$ per day) or low ( $\leqslant 200 \mu \mathrm{g}$ per day) doses of FP. ${ }^{11}$ The time taken to reach either $50 \%$ or $100 \%$ of the best observed effect was no longer in the low dose group, once again demonstrating no reduction in different parameters of efficacy.

The major limitation of these metaanalyses was the small number of studies that included FP doses of $1000 \mu \mathrm{g}$ per day or more, due to the requirement for the studies to be placebo controlled. This led to a subsequent meta-analysis which specifically focused on comparisons between a dose of $200 \mu \mathrm{g}$ per day and higher doses to determine whether the $200 \mu \mathrm{g}$ per day dose regime provided most of the therapeutic benefit as suggested in the original study. ${ }^{8}$ It was confirmed that most of the therapeutic effect was achieved with a dose of $200 \mu \mathrm{g}$ per day, and that an increase in dose to $\geqslant 500 \mu \mathrm{g}$ per day resulted in minimal additional benefit.

Another meta-analysis with inhaled budesonide has shown that most of the clinical efficacy for the same outcome measures is achieved with a dose of around $400 \mu \mathrm{g}$ per day. ' Likewise, a large dose-response study of BDP showed a plateau in response between 400 and $800 \mu \mathrm{g}$ per day, depending on the clinical outcome variable. ${ }^{12}$ These findings are comparable with those of FP when their relative potencies are considered (FP $v$ budesonide or BDP around 2:1).

Another consideration is whether a different dose-response relationship exists for inhaled corticosteroids in terms of modifying the underlying airways inflammation. Only a few studies have addressed this issue because of the requirement for repeated bronchoscopic examinations to obtain bronchial biopsy and lavage samples. These studies have reported no additional effect on either the nature or magnitude of the airways inflammation with increasing the dose of FP from $400-500 \mu \mathrm{g}$ per day to 1000 $2000 \mu \mathrm{g}$ per day. ${ }^{13}{ }^{14}$ As a result, the dose-response relationship of inhaled corticosteroids for anti-inflammatory effects in the airways appears to be similar to that for the clinical outcome measures.

The major clinical outcome measure which could not be assessed in doseresponse studies is mortality because of its rare occurrence even in patients with severe asthma. However, it is possible to obtain an indication of the doseresponse effect of inhaled corticosteroids for reducing the risk of mortality from the epidemiological study reported by Suissa et al. ${ }^{15}$ In this study there was a 
progressive reduction in risk of mortality with increasing use of inhaled corticosteroids. Consistent with the major clinical outcome measures, at least $80 \%$ of the maximum obtainable benefit (reduction in mortality) was achieved at around $200 \mu \mathrm{g}$ BDP per day (adjusted odds ratio 0.15). As a result, available evidence suggests that low doses of inhaled corticosteroids are effective in reducing the risk of death from asthma, with a dose response similar to that of other major outcome variables such as symptoms, lung function, and severe exacerbations.

Based on these studies, it can be recommended that the standard dose of inhaled corticosteroid for routine prescribing in adult asthma is around $400 \mu \mathrm{g}$ per day BDP or budesonide, or $200 \mu \mathrm{g}$ per day FP. This recommendation should be qualified by the recognition that there is considerable variability between individuals in their response to inhaled corticosteroids in asthma, which means that some patients may obtain a greater clinical benefit at higher doses, just as some patients may obtain the maximum efficacy at lower doses. ${ }^{16}$

So what is the priority now in terms of research into the use of inhaled corticosteroid therapy in asthma? Currently, the major dilemma for clinicians is to know at what dose of inhaled corticosteroids to start concomitant long acting $\beta$ agonist (LABA) therapy in a patient inadequately controlled on inhaled corticosteroids alone. This uncertainty is reflected by the different guideline recommendations to add a LABA over a fivefold inhaled corticosteroid dose range $(200-1000 \mu \mathrm{g}$ per day BDP or equivalent)..$^{2-5}$ Determination of the dose of inhaled corticosteroids at which to add a LABA as first line add-on therapy at step 3 of the guidelines will probably also require a meta-analytical approach. Elucidation of the optimal starting dose and the therapeutic dose range of inhaled corticosteroids has provided important information for the planning of such a metaanalysis.

Thorax 2005;60:93-94.

doi: $10.1136 /$ thx.2004.031179

\section{Authors' affiliations}

M Masoli, R Beasley, Medical Research Institute of New Zealand, Wellington, New Zealand

M Weatherall, Wellington School of Medicine \& Health Sciences, Wellington, New Zealand R Beasley, University of Southampton,

Southampton, UK

Correspondence to: Professor R Beasley, Medical Research Institute of New Zealand P O Box 10055, Wellington, New Zealand; Richard.Beasley@mrinz.ac.nz

\section{REFERENCES}

1 Barnes PJ, Pedersen, Busse W. Efficacy and safety of ICS: new developments. Am J Respir Crit Care Med 1998;157(3 Pt 2):S1-39.

2 National Asthma Council. Asthma management handbook, National Asthma Council, 2002.

3 New Zealand Guidelines Group. Best practice evidence-based guideline: the diagnosis and treatment of adult asthma, New Zealand Guidelines Group, 2002:101.

4 Global Initiative for Asthma. Global strategy for asthma management and prevention, $\mathrm{NHLBI} /$
WHO Workshop Report. Bethesda, MD: National Institutes of Health, National Heart, Lung and Blood Institute, 2002

5 British Thoracic Society/Scottish Intercollegiate Guidelines Network. British guideline on asthma management: a national clinical guideline. Thorax 2003;58(Suppl I):i1-94.

6 Powell H, Gibson PG. Initial starting dose of inhaled corticosteroids in asthma for adults: a systematic review. Thorax 2004;59:1041-5.

7 Holt S, Suder A, Weatherall M, et al. Doseresponse relation of inhaled fluticasone propionate in adolescents and adults with asthma: meta-analysis. BMJ 2001;323:253-6.

8 Masoli M, Weatherall M, Holt S, et al. Clinical dose-response relationship of fluticasone propionate in adults with asthma. Thorax 2004:59:16-20.

9 Masoli M, Holt S, Weatherall M, et al. Doseresponse relationship of inhaled budesonide in adult asthma: a meta-analysis. Eur Respir J 2004;23:1-7.

10 Bousquet J, Ben-Joseph R, Messonnier M, et al. A meta-analysis of the dose-response relationship of inhaled corticosteroids in adolescents and adults with mild to moderate persistent asthma. Clin Ther 2002;24:1-20.

11 Szefler SJ, Bousher HA, Pearlman DS, et al. Time to onset of effect of fluticasone propionate in patients with asthma. J Allergy Clin Immunol 1999; 103:780-8.

12 Busse WW, Brazinsky S, Jacobson K, et al. Efficacy response of inhaled beclomethasone dipropionate in asthma is proportional to dose and is improved by formulation with a new propellant J Allergy Clin Immunol 1999;104:1215-22.

13 Wallin A, Sue-Chu M, Bjermer L, et al. Effect of inhaled fluticasone with and without salmeterol on airway inflammation in asthma. J Allergy Clin Immunol 2003;112:72-8.

14 O'Sullivan S, Cormican L, Murphy M, et al. Effects of varying doses of fluticasone propionate on the physiology and bronchial wall immunopathology in mild-to-moderate asthma. Chest 2002; 122:1966-72.

15 Suissa S, Ernst P, Benayoun S, et al. Low-dose inhaled corticosteroids and the prevention of death from asthma. N Engl J Med 2000;343:332-6.

16 Szefler SJ, Martin RJ, King TS, et al. Significant variability in response to inhaled corticosteroids for persistent asthma. J Allergy Clin Immunol 2002; 109:410-8.

\section{Some consensus but little evidence: guidelines on management of pleural infection in children}

\section{M Balfour-Lynn}

\section{A review of the newly published guidelines on the management of pleural infection in children}

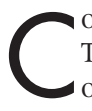
ommissioned by the British Thoracic Society (BTS) Standards of Care Committee, the BTS guidelines for the management of pleural infection in children are published as a supplement to this month's issue of Thorax. ${ }^{1}$ They have also been subject to scrutiny by the Quality of Practice
Committee (QPC) of the Royal College of Paediatrics and Child Health (RCPCH) using the AGREE appraisal instrument, and consequently have been endorsed by the RCPCH. So why did we write them and was it worth it? More importantly-should you read them? What follows are my views as chair of the guideline committee and may not represent those of the other members of the committee (listed in the Acknowledgements).

\section{WHY DID WE WRITE THEM?}

We are not paediatricians for nothingwe understand sibling rivalry-so when the adult respiratory physicians got an empyema guideline, ${ }^{2}$ we wanted one. However, it was more than just that. There are major differences between adult and paediatric pleural infections. The principal one is that most children are fit and well before they contract pneumonia and develop an empyema, so the outcome is almost always excellent. This is in contrast to the disease in adults where empyema is a cause of significant morbidity and mortality (recent data has revealed a 12\% mortality rate even in those without cancer $^{3}$ ). Nevertheless, management of childhood empyema can still be a therapeutic challenge. Unfortunately, in the UK 
there is little consensus over best practice, both among respiratory paediatricians and also thoracic surgeons. It was therefore considered important to synthesise the available evidence and write guidelines, even though they may only point people in the right direction and highlight the unresolved issues. It is hoped that the guidelines will facilitate dissemination of evidence and standardisation of patient care. While they are principally aimed at the UK, they are applicable to children worldwide. The principal differences in management from the UK will concern predominant local pathogens, availability of antibiotics and fibrinolytics, and availability of trained personnel.

\section{HOW DID WE WRITE THEM?}

For anyone unfamiliar with the process of writing a guideline, the website of the Scottish Intercollegiate Guideline Network (SIGN) is invaluable (www. sign.ac.uk) and we followed their process for producing levels of evidence and grades of recommendations. Literature searching was extensive and professional (library of National Heart Lung Institute) and the search strategy is included as an appendix to the guidelines. It was kept up to date and rechecked by individual members responsible for a particular topic. We ensured the make-up of the guideline committee included all the relevant disciplines: a general/emergency paediatrician, respiratory paediatricians (including a trainee), a paediatric and thoracic surgeon, a microbiologist and a radiologist. We also ensured that representatives of the different major viewpoints were included (readily iden-
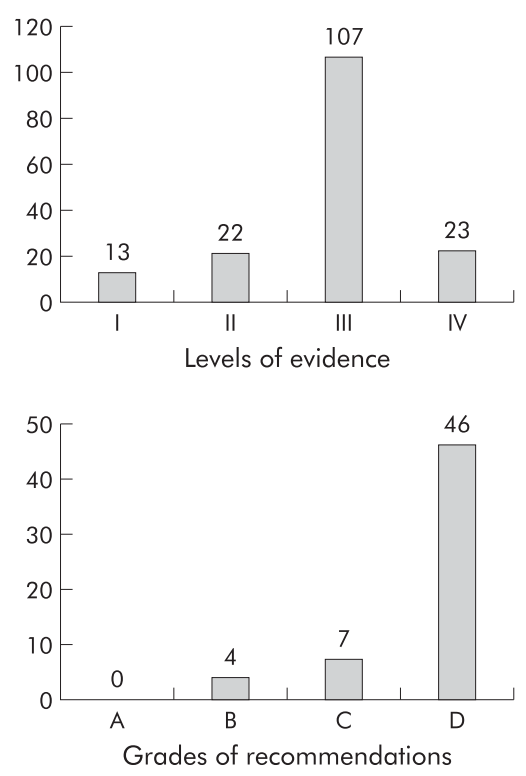

Figure 1 Levels of evidence and grades of recommendation using SIGN ratings.' tifiable from previous pro/con debates). With the use of email, only one meeting was required with the whole group. Where there was no evidence we relied on "expert opinion" and, while we did not use a formal consensus technique, the guidelines are a fair reflection of the opinions of the whole committee as well as the specialist reviewers. It was pointed out by the RCPCH that we did not have "consumer input". While I would agree that guidelines on chronic diseases such as asthma or cystic fibrosis benefit from patient/parent input, I do not believe this to be case with a oneoff acute condition such as an empyema where parents will not have gained a particular expertise. The guidelines went through several review stages including the BTS Standards of Care Committee, specialist reviewers (listed below), and the RCPCH QPC. Our thanks are due to them all for their valuable contributions.

\section{WHAT PROBLEMS DID WE ENCOUNTER?}

Guidelines need to be evidence-based, so this immediately presented a problem as there is a lack of evidence from randomised controlled trials for almost all the relevant issues in childhood empyema. In addition, it is inappropriate simply to extrapolate adult data to children, particularly when the condition behaves so differently in the two populations. Why so few trials? Empyema has until recently been relatively rare in developed countries. Over the last decade there has been a noticeable increase both in the UK and the USA $;^{1}$ in our own institution 20 cases were reported during the 5 year period from 1990 to 1994 inclusive, ${ }^{4}$ whereas we now see that many cases each year. While this may reflect a change in referral patterns, undoubtedly there has been a genuine increase in incidence. In the UK the predominant pathogen is penicillin-sensitive pneumococcus, while in developing countries it is still Staphylococcus aureus. ${ }^{1}$ It is possible that the increased incidence in the UK coincides with a reduction in antibiotic prescribing in primary care. ${ }^{5}$ Although it is good that less amoxicillin is given to "chesty" children with viral upper respiratory tract infections, the cost may be a missed opportunity for early treatment of the few children with genuine pneumonia.

As management of empyema became more of an issue, the British Paediatric Respiratory Society Empyema Study Group (led by Anne Thomson in Oxford) performed the only major placebo controlled randomised trial in childhood empyema-a multicentre trial of intrapleural urokinase that still took two winters to enrol 60 cases. ${ }^{6}$ This trial provided three of the four SIGN grade $\mathrm{B}$ recommendations in the guidelines. The only other grade B recommendation was related to using microbiology results to guide antibiotic choice (grade taken from adult guidelines), but even then the RCPCH QPC downgraded that to a D. There was not a single grade A recommendation, seven grade Cs, and 46 grade Ds (fig 1). This means that $80 \%$ of our recommendations were based on evidence taken from case reports, case series, and expert opinion. This should not be used as a criticism of the guidelines; it is simply a reflection of the available evidence. In addition, many of the grade D recommendations are based on safe current practice and common sense. No one can deny that "analgesia is important to keep the child comfortable, particularly in the presence of a chest drain", a grade $\mathrm{D}$ recommendation that never has been (nor ever should be) subjected to a randomised controlled trial. Perhaps SIGN should come up with an extra grade (E) - no evidence but blindingly obvious. Our grade D recommendation that "all children with parapneumonic effusion or empyema should be admitted to hospital" would fit that category. Evidence from randomised controlled trials should not be the only resource that informs guidelines, and clinical experience should not be excluded.

\section{WHAT DID WE RECOMMEND?}

There are 57 bulleted recommendations with accompanying explanatory text and one algorithm summarising management. The guidelines need reading in full, but there are a few points worth highlighting. There is no role for routine lateral chest radiographs or CT scans; plain chest radiographs and ultrasound are sufficient and will reduce the radiation burden. Pleural fluid must be sent for cell differential counting (or cytology) as well as microbiological analysis, but there is nothing to gain from biochemical analysis (such as $\mathrm{pH}$, glucose, protein, lactate dehydrogenase). If there is any suspicion of malignancy, a small volume diagnostic tap for cytological testing is needed, where possible avoiding general anaesthesia/sedation to prevent potentially disastrous superior mediastinal obstruction. Significant effusions should be drained from the outset; repeated taps are not recommended.

We recommend that a respiratory paediatrician should be involved early in the care of all patients requiring chest tube drainage for an empyema. We feel strongly that this condition should be looked after in tertiary centres, not least because of the nursing expertise 
required to safely manage chest drains. Empyema is still relatively uncommon and, given the uncertainties over management, we feel it is not ideal for patients to be treated in a general paediatric unit that might only treat one or two cases a year. To an extent this recommendation for referral is happening anyway, partly because constraints imposed by junior doctor working hours and the European Working Time Directive mean that many paediatric specialist registrars are no longer experienced at chest drain insertion. We also find that many anaesthetists in district general hospitals are now unwilling to anaesthetise children with respiratory compromise. Interestingly, this recommendation-which I believe to be one of the most important in the whole guideline-was the only one that the RCPCH QPC was not keen on publishing in the version due to be sent to all UK paediatricians. Clearly, there will be circumstances when it is unnecessary or not in the child's best interest to move large distances, but there is a concern that medicolegal consequences may follow if management goes wrong outside a tertiary centre.

We have suggested some antibiotic regimens but local antibiotic policies and likely pathogens should also be taken into account. There is no evidence that large bore drains confer any advantage over small ones, but they certainly cause more pain and reduce mobility, so small ones (8-12 FG) should be used where possible. They should be placed at the optimum site suggested by ultrasound, but not too far posteriorly as they are uncomfortable to lie on and there is a greater risk of traumatic bleeding from the posterior intercostal spaces. One of the more contentious issues was whether drains should be inserted under general anaesthesia or sedation with local anaesthesia. Most anaesthetists would not endorse intravenous sedation (especially in a child with respiratory compromise), but a definitive anaesthetic guideline does not exist to clarify this issue. Personally, I believe a general anaesthetic is kinder for the child (especially younger ones); it also makes the procedure easier and allows time for a long line to be inserted. The compromise for the guidelines was our recommendation that intravenous sedation should only be given by those trained in the use of conscious sedation, airway management and resuscitation of children, using full monitoring equipment-something which I suspect will rule out many paediatricians anyway.
For those having the medical option (see algorithm of guideline), based on a randomised controlled trial, ${ }^{6}$ use of intrapleural urokinase is recommended when there is thick fluid with loculations or overt pus. The biggest issue is the role of surgery as primary treatment. There is little dispute that failure of chest tube drainage, antibiotics, and fibrinolytic agents should prompt discussion with a thoracic surgeon, and that patients should be considered for surgical treatment if they have persisting sepsis in association with a persistent pleural collection. The issue where consensus cannot be reached in the UK is the role of medical versus early surgery and, if surgery is chosen, whether a mini-thoracotomy or video assisted thoracoscopic surgery (VATS) is superior. There are no trial data to inform the decision; however, there are many case series, mostly written by enthusiasts of their own technique, using historical "controls". For this reason our guideline gives medical and surgical options in the management algorithm. For now, units should continue to manage their cases using their own established and familiar practices, in whatever way they feel is best from their own experiences. Available resources may also affect local policy, especially in health services with financial constraints. Parents and children need to be fully informed of the options (good patient information sheets are essential), but ultimately they are likely to be swayed by the opinion of the treating doctors and nurses. In the case series of 20 patients treated at the Royal Brompton Hospital during 1990-4, 65\% had immediate surgery but $90 \%$ eventually required surgery; ${ }^{4}$ currently, with the use of small drains and urokinase, only $5-10 \%$ require surgery in our centre. What is needed is an understanding of the factors that predict failure of medical management, as these children could then be selected for immediate surgery while the rest could have simple medical management.

\section{FUTURE RESEARCH}

The guidelines offer a list of potential areas for future clinical research. In terms of management, the issue of drain/fibrinolytics versus early minithoracotomy versus VATS is the outstanding one. Since the outcome is generally so good in terms of clinical recovery, lung function and chest radiographic appearance (whatever the treatment), it will be difficult to prove one better than another, and most treatment regimens will show equivalence. Pain and discomfort must be taken into account, not just days in hospital, as most children would prefer an extra day or so in hospital if it meant significantly less pain. It is likely that large multicentre trials will be necessary to make any serious progress, although there is an ongoing study at Great Ormond Street Hospital for Children comparing intrapleural urokinase with early VATS in a randomised non-blinded trial.

\section{CONCLUSIONS}

I will conclude by quoting a statement from the RCPCH guideline appraisal: "Guidelines are not intended to restrict clinical freedom, but practitioners are expected to use the recommendations as a basis for their practice. Local resources and the circumstances and preferences of individual patients will need to be taken into account". This is certainly true of childhood empyema and, yes, these BTS guidelines should be read.

\section{ACKNOWLEDGEMENTS}

Paediatric Pleural Diseases Subcommittee of the BTS Standards of Care Committee: Dr I M Balfour-Lynn (Chair), Dr E Abrahamson, Mr G Cohen, Dr J Hartley, Dr S King, Mr D Parikh, Dr D Spencer, Dr A H Thomson, Dr D Urquhart. Also Dr B G Higgins (past Chair), Dr D Boldy (present Chair) and the other members of the BTS Standards of Care Committee.

Specialist reviewers: Dr R Dinwiddie, Dr I Doull, Mr P Goldstraw, Dr R A Primhak, Dr P Seddon. Also Dr H Baumer (Chair) and other members of RCPCH Quality of Practice Committee.

Thorax 2005;60:94-96.

doi: $10.1136 /$ thx.2004.038406

Correspondence to: Dr I M Balfour-Lynn, Department of Paediatric Respiratory Medicine, Royal Brompton Hospital, Sydney Street, London SW3 6NP, UK; i.balfourlynn@imperial. ac.uk

\section{REFERENCES}

1 Balfour-Lynn IM, Abrahamson A, Cohen G, et al. BTS guidelines for the management of pleural infection in children. Thorax 2005;60(Suppl I):i1-21.

2 Davies CH, Gleeson FV, Davies RJO. BTS guidelines on the management of pleural infection. Thorax 2003;58(Suppl II):ii18-28.

3 Maskell NA, Davies CWH, Ghabe R, et al. Predictors of survival in patients with pleural infection but without cancer: results from the MRC/BTS MIST Trial, ICTN 39138989. Thorax 2004;59(Suppl II):ii40.

4 Khakoo GA, Goldstraw P, Hansell DM, et al. Surgical treatment of parapneumonic empyema. Pediatr Pulmonol 1996;22:348-56.

5 Ashworth M, Latinovic R, Charlton J, et al. Why has antibiotic prescribing for respiratory illness declined in primary care? A longitudinal study using the General Practice Research Database. J Public Health (Oxford) 2004;26:268-74.

6 Thomson AH, Hull J, Kumar MR, et al. Randomised trial of intrapleural urokinase in the treatment of childhood empyema. Thorax 2002;57:343-7. 